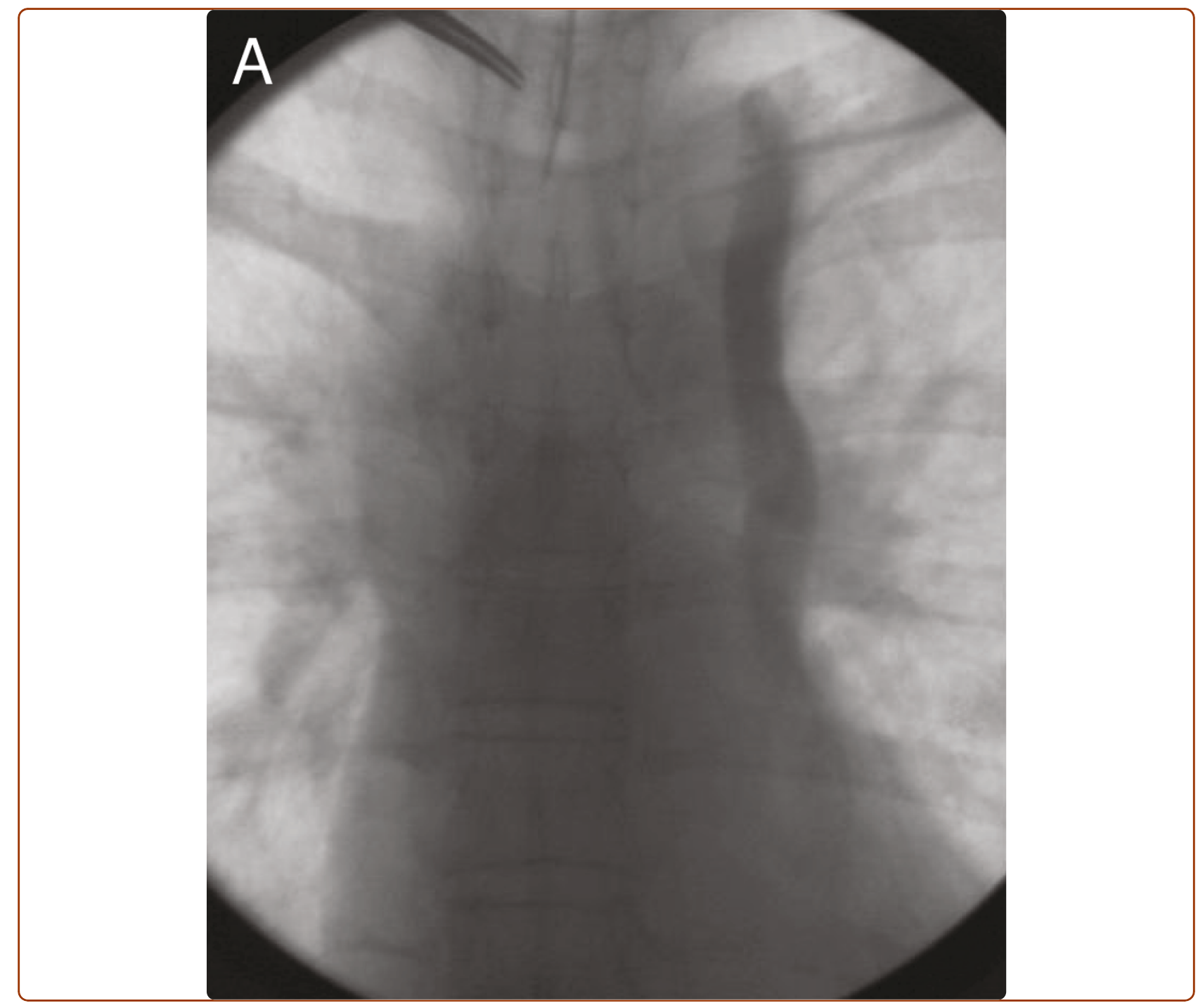

Persistent left superior vena cava: Review of the literature, clinical implications, and relevance of alterations in thoracic central venous anatomy as pertaining to the general principles of central venous access device placement and venography in cancer patients

Povoski and Khabiri 


\title{
Persistent left superior vena cava: Review of the literature, clinical implications, and relevance of alterations in thoracic central venous anatomy as pertaining to the general principles of central venous access device placement and venography in cancer patients
}

\author{
Stephen P Povoski ${ }^{*}$ and Hooman Khabiri ${ }^{2}$
}

\begin{abstract}
Persistent left superior vena cava (PLSVC) represents the most common congenital venous anomaly of the thoracic systemic venous return, occurring in $0.3 \%$ to $0.5 \%$ of individuals in the general population, and in up to $12 \%$ of individuals with other documented congential heart abnormalities. In this regard, there is very little in the literature that specifically addresses the potential importance of the incidental finding of PLSVC to surgeons, interventional radiologists, and other physicians actively involved in central venous access device placement in cancer patients. In the current review, we have attempted to comprehensively evaluate the available literature regarding PLSVC. Additionally, we have discussed the clinical implications and relevance of such congenital aberrancies, as well as of treatment-induced or disease-induced alterations in the anatomy of the thoracic central venous system, as they pertain to the general principles of successful placement of central venous access devices in cancer patients. Specifically regarding PLSVC, it is critical to recognize its presence during attempted central venous access device placement and to fully characterize the pattern of cardiac venous return (i.e., to the right atrium or to the left atrium) in any patient suspected of PLSVC prior to initiation of use of their central venous access device.
\end{abstract}

Keywords: central venous access, venography, cancer, persistent left superior vena cava, superior vena cava

\section{Background}

Central venous access device placement is a commonplace practice for many physicians, including surgeons, interventional radiologists, and other physicians, who are involved in the management of cancer patients [1]. Yet, successful placement of such central venous access devices can sometimes be very challenging. Therefore, having a thorough understanding of venous anatomy, including the recognition of congenital venous

\footnotetext{
* Correspondence: stephen.povoski@osumc.edu

'Division of Surgical Oncology, Department of Surgery, Arthur G. James

Cancer Hospital and Richard J. Solove Research Institute and Comprehensive Cancer Center, The Ohio State University Medical Center, Columbus, Ohio,

43210, USA

Full list of author information is available at the end of the article
}

anomalies and the recognition of treatment-induced or disease-induced alterations in thoracic central venous anatomy, as well as having a good working knowledge of alternative and supplemental strategies for placement of central venous access devices, are critical factors to maximizing the success of device placement and to minimizing the risk of potential complications [1-5].

The aim of the current report is to review the available literature as it pertains to the specific congential venous anomaly of the thoracic systemic venous return, persistent left superior vena cava (PLSVC), and to discuss the clinical implications and relevance of congenital aberrancies, as well as of treatment-induced or diseaseinduced alterations in the anatomy of the thoracic central venous system, as they pertain to the general 
principles of central venous access device placement and venography. A thorough understanding of such principles is of upmost importance to surgeons, interventional radiologists, and other physicians whom are actively involved in central venous access device placement in cancer patients.

\section{Case report}

The patient was a 53 year old Caucasian woman, without any previous major medical problems, who was recently diagnosed with synchronous bilateral breast cancers and who underwent a right modified radical mastectomy and a left total mastectomy and left axillary sentinel lymph node biopsy for a pT2, pN1, estrogen receptor positive, progesterone receptor positive, HER$2 /$ neu negative invasive lobular carcinoma of the right breast and a pT1b, pN0, estrogen receptor positive, progesterone receptor positive, HER-2/neu negative invasive ductal carcinoma of the left breast, respectively. The patient was subsequently recommended for placement of a subcutaneous implanted port for administration of postoperative adjuvant systemic chemotherapy.

Therefore, the patient was taken to the operating room by the surgeon for subcutaneous port placement. At the request of the patient, this procedure was done under general anesthesia. The left side was selected, as it represented the side of her earlier-stage breast cancer. A left cephalic vein cutdown approach was undertaken in the left lateral infraclavicular region, by the methodology as previously described by Povoski [4]. Upon creating a transverse venotomy in the anterior wall of the left cephalic vein and passing a 9.6 French single lumen silicone catheter centrally, it was noted on real-time intraoperative fluoroscopy of the thoracic region that the 9.6 French single lumen silicone catheter eventually advanced downward in a craniocaudal fashion along the left paramediastinal border. As a result of this finding, intraoperative venography (Figure 1) was undertaken by the surgeon in a non-digital subtraction fashion through the 9.6 French single lumen silicone catheter and at several distances from the entry point into the left cephalic vein, as the 9.6 French single lumen silicone catheter was sequentially advanced from approximately the $8 \mathrm{~cm}$ mark to the $15 \mathrm{~cm}$ mark. A total of approximately 50 milliliters of iohexol injectable contrast $(300 \mathrm{mg} / \mathrm{mL})$ was utilized during intraoperative venography. With the tip of the 9.6 French single lumen silicone catheter first positioned in the region of the mid-portion of the left subclavian vein, but at a point at which some resistant to further advancement of the 9.6 French single lumen silicone catheter was noted, intraoperative venography performed through the 9.6 French single lumen silicone catheter (Figure 1A) revealed a small (3 to $4 \mathrm{~mm}$ ) venous branch off of the left subclavian vein that was first directed horizontally for approximately 3 to $4 \mathrm{~cm}$ and then was re-directed cephalad in a rightward direction across the upper thorax/lower neck region. Just before the transition from the horizontal to cephalad portion of this small ( 3 to $4 \mathrm{~mm}$ ) venous branch off of the left subclavian vein, a tiny ( 1 to $2 \mathrm{~mm}$ ) venous tributary was seen to originate off of the small (3 to $4 \mathrm{~mm}$ ) venous branch. This tiny ( 1 to $2 \mathrm{~mm}$ ) venous tributary was noted to meander in a generalized horizontal fashion across the midline of the upper thorax region and into the contralateral right hemi-thorax region. Subsequently, after repositioning of the 9.6 French single lumen silicone catheter and overcoming the previous resistence to catheter advancement, and with the tip of the 9.6 French single lumen silicone catheter now positioned more centrally (but still horizontally) in the region of the left subclavian vein (Figure 1B), and then with further catheter advancement with the tip of the
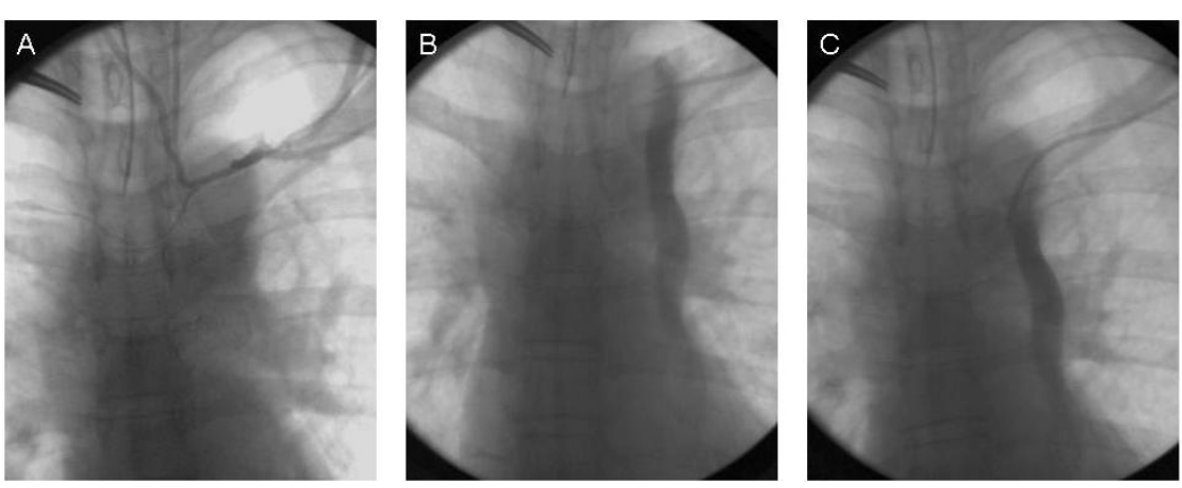

Figure 1 Intraoperative venography performed by standard fluoroscopy in a non-digital subtraction fashion through a 9.6 French single lumen silicone catheter by way of a left cephalic vein cutdown approach. (A) Catheter tip is positioned in the region of the midportion of the left subclavian vein at a point at which some resistant to further advancement of the catheter was noted. (B) Catheter tip is positioned more centrally, but still horizontally, in the region of the left subclavian vein. (C) Catheter tip is positioned even more centrally and in a craniocaudal direction in the upper left paramediastinal border region. 
9.6 French single lumen silicone catheter then positioned even more centrally in a craniocaudal fashion in the upper left paramediastinal border region (Figure $1 \mathrm{C})$, intraoperative venography revealed the presence of a relatively large diameter craniocaudally-oriented venous structure located to the left side of the midline in the medial left hemi-thorax region in a location adjacent to the cardiomediastinal silhouette and which appeared to eventually drain into the cardiac silhouette. There was absence of visualization of an identifiable left innominate vein on intraoperative venography. This relatively large diameter craniocaudally-oriented venous structure coursing downwards on the left side of the midline in the medial left hemi-thorax region was intraoperatively suspected by the surgeon to represent a PLSVC.

Same-day consultation with the interventional radiologist revealed a similar opinion. However, based upon the intrinsic limitations of the non-digital subtraction intraoperative venography procedure performed, an accurate assessment of the point of insertion of the PLSVC into the venous return of the heart and the anatomy of the contralateral right-sided central venous system could not be adequately determined. Therefore, subsequent standard digital subtraction venography was recommended by the interventional radiologist.

The subcutaneous port placement procedure was uneventfully completed by the surgeon by placing the tip of the 9.6 French single lumen silicone catheter to approximately the $15 \mathrm{~cm}$ mark within the recognized PLSVC and attaching the 9.6 French single lumen silicone catheter to an implantable port (Titanium Bard PowerPort, C. R. Bard, Inc., Salt Lake City, UT) and closing the port insertion surgical skin incision site that was located in the left lateral infraclavicular region.
A subsequent posterioranterior and lateral chest $\mathrm{x}$-ray (Figure 2) was performed and demonstrated the implanted left-sided subcutaneous port and the attached 9.6 French single lumen silicone catheter and its course along the medial left hemi-thorax region in a location adjacent to the cardiomediastinal silhouette, consistent with PLSVC.

In the subsequent weeks after left-sided subcutaneous port placement, digital subtraction venography of the left-sided central venous system (by way of the left-sided subcutaneous port) (Figure 3) and digital subtraction venography of the right upper extremity veins and rightsided central venous system (by way of a peripheral vein in the dorsum of the right hand) (Figure 4) were both performed by the interventional radiologist within the interventional radiology suite.

At approximately two weeks after left-sided subcutaneous port placement, the patient underwent digital subtraction venography of the left-sided central venous system by way of the left-sided subcutaneous port (Figure 3), in order to fully characterize the central venous drainage pathway of the PLSVC (i.e., the point of confluence of the PLSVC with the venous return of the heart). The left-sided subcutaneous port reservoir was accessed in a sterile fashion using an 18-gauge Huber needle. Power injections were performed at $5 \mathrm{~mL} / \mathrm{sec}$ ond of iodixanol injectable contrast $(320 \mathrm{mg} / \mathrm{mL})$, with maximum injection pressure set at 300 PSI. Digital subtraction imaging was performed at 6 frames/second during the power injection. Digital subtraction venography confirmed that the point of confluence of the PLSVC with the venous return of the heart was at the right coronary sinus and into an atrial structure within the cardiac silhouette (Figure 3A). Delayed digital subtraction images demonstrated that the atrial structure then drained into the right ventricle and subsequently
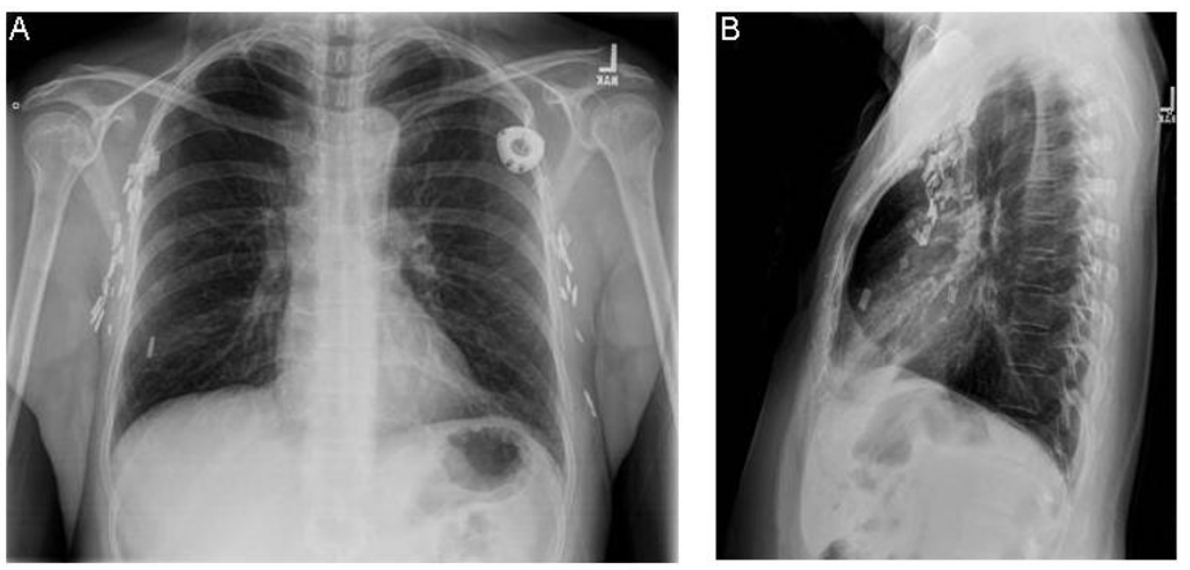

Figure 2 Posterioranterior (A) and lateral (B) chest $\mathrm{x}$-ray views 

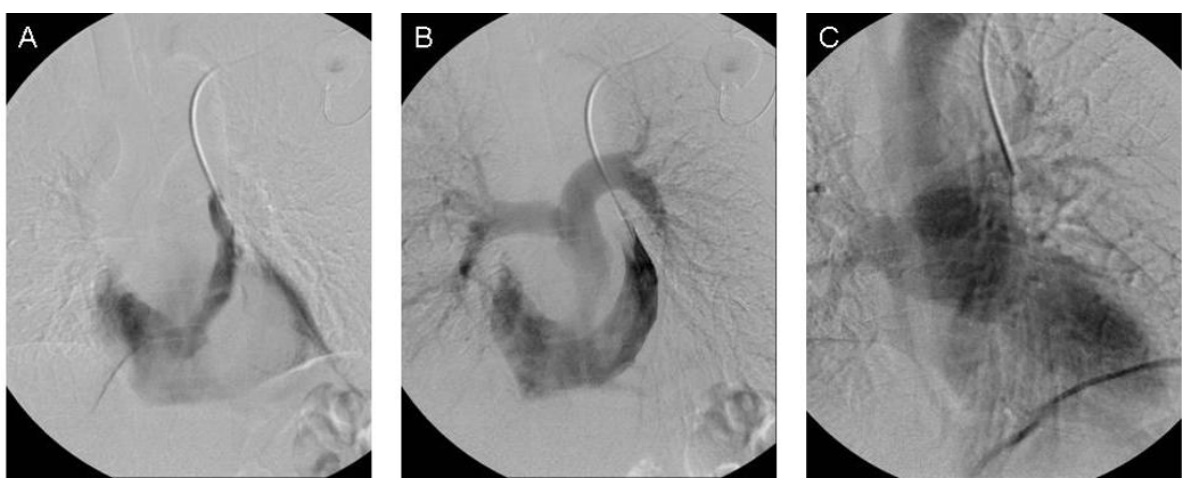

Figure 3 Digital subtraction venogram of the left-sided central venous system performed by way of the left-sided subcutaneous port.

into the pulmonary arteries (Figure 3B), confirming that the atrial chamber receiving the venous return from the PLSVC was indeed the right atrium. Further later delayed digital subtraction images demonstrated the pulmonary venous return and the filling of the left side of the heart and subsequent aortic outflow (Figure 3C). There was no evidence of early arterial filling. There was no evidence of right to left shunting on the early images, nor was there evidence of left to right shunting on the delayed images.

Approximately four weeks later, the patient underwent digital subtraction venography of the right upper extremity veins and the right-sided central venous system by way of a peripheral vein in the dorsum of the right hand (Figure 4), in order to fully characterize the right-sided peripheral and central venous anatomy. A vein in the dorsum of the right hand was accessed in a sterile fashion using an 18-gauge angiocatheter. Power injections were performed at $3 \mathrm{~mL} /$ second of iodixanol injectable contrast $(320 \mathrm{mg} / \mathrm{mL})$, with maximum injection pressure set at 600 PSI. Digital subtraction imaging was performed at 3 frames/second during the power injection. Digital subtraction venography demonstrated normal venous anatomy within the right forearm and right upper arm regions. The more central right-sided veins, including the right axillary vein and right subclavian vein were also normal in appearance. Incidentally, there was partial fenestration of a portion of the right subclavian vein, a commonly encountered venous entity, which is usually of no clinical significance. Her right superior vena cava (SVC) was somewhat smaller in caliber than is usually seen in someone without a co-existing PLSVC. However, her right SVC was approximately of the same size as her PLSVC that was seen on her prior venography imaging. The right SVC venous return to the heart was into the right atrium, and without venographic evidence of right-to-left shunting or left-toright shunting. The venous flow from the right atrium was identical to that seen during the previous digital subtraction venogram of the left-sided central venous system performed by way of the left-sided subcutaneous port.

Thereafter, the patient was allowed to use her leftsided subcutaneous port for continued administration of postoperative adjuvant systemic chemotherapy, blood draws, and all necessary subsequent contrast-based imaging. The patient had no detectable problems during the utilization of her left-sided subcutaneous port and had no resultant complications. The patient's left-sided subcutaneous port was eventually removed after she completed her postoperative adjuvant systemic chemotherapy, some seven months after its original placement.

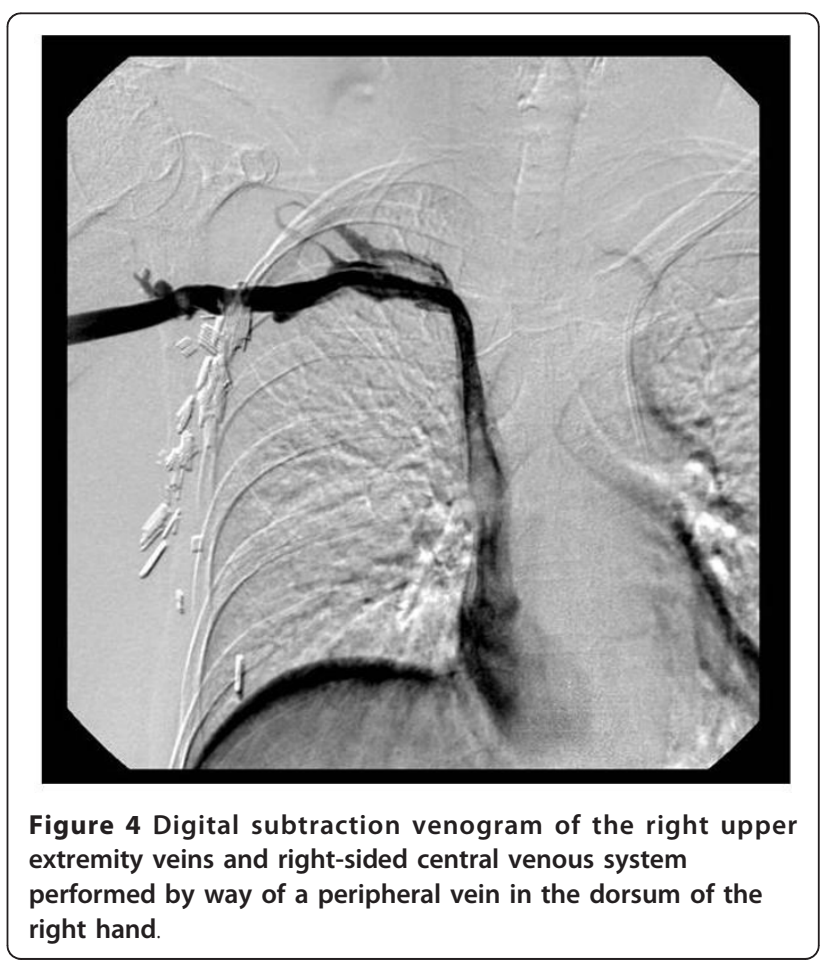




\section{Review \\ Origins of the first description and available literature on PLSVC}

The exact origin of the first description of PLSVC remain a matter of much great debate within the historical scientific literature, although it appears to have likely occurred at some time during the $17^{\text {th }}$ century to $18^{\text {th }}$ century $[6,7]$. Some have accredited the recognition of the first description of PLSVC to the work of various individuals during that time period, including the Danish physician Thomas Bartholin (1616-1680) [6-9], the English surgeon William Cheselden (1688-1752) $[6,7,10,11]$, the French surgeon Claude-Nicolas Le Cat (1700-1768) [6,12,13], the Swiss physician Albrecht von Haller (1708-1777) [6,7,14], the German physician Philipp Adolf Boehmer (17111789) $[6,7,15]$, and the Swedish surgeon Adolph Murray (1750-1803) $[6,7,16,17]$. However, the first in-depth review on the topic of the great anterior veins of the thoracic region, including PLSVC, in man and mammals, was published in 1850 by John Marshall (1818-1891), an English surgeon and teacher of anatomy at University College Hospital in London [6].

Since that time, a plethora of, and too numerous to cite, papers have been published on various aspects of PLSVC, including characterization of central venous anatomy and central venous anomalies, embryologic development of the central venous system, identification of PLSVC during implantable pacemaker and cardioverter defibrillator placement, identification of PLSVC during various forms of central venous access device placement, impact of PLSVC on various cardiac surgery procedures, and indications for surgical correction of PLSVC. To date, in PubMed.gov [18], a search of the key words "left superior vena cava" reveals 3109 citations and a search of the key words "persistent left superior vena cava” reveals 923 citations. Some more historical reports on PLSVC [6,7,19-30] and some review-style reports on PLSVC [31-44] are worth mentioning for further reading and have been cited within the current paper.

Those papers in the literature that have specifically addressed the incidental finding of PLSVC at the time of placement of some sort of central venous access device or some sort of central venous monitoring device [38,42,44-123] have generally been directed towards physicians practicing anesthesia $[47,48,52,55,58-60$, $62,64,65,68-71,73,78,85,88,91,92,94,102,117,120,123]$, critical care $[45,46,49-51,53,56,57,72,77,79,83,106,109$, $110,114,116,119,122]$, and nephrology $[54,66,74$, $76,80,87,95,96,100,103,104,107,108,113,118]$. Despite the fact that a plethora of papers have been published on various aspects of PLSVC and despite there being multiple case reports describing the incidental finding of
PLSVC at the time of central venous device placement, there has been very little in the literature specifically directed toward the potential importance of the incidental finding of PLSVC to surgeons, interventional radiologists, and other physicians who are actively involved in central venous access device placement in cancer patients $[61,81,82,84,111]$.

\section{Incidence of PLSVC}

PLSVC represents the most common congenital venous anomaly of the thoracic systemic venous return $[36,43]$. It is reported to occur in only $0.3 \%$ to $0.5 \%$ of individuals in the general population, thus representing an occurrence in only 1 in every 200 people to only 1 in every 325 people. However, since the vast majority of cases of this congenital venous anomaly are asymptomatic, its true incidence in the general population may actually be difficult to accurately establish [43]. Nevertheless, it is reported that PLSVC may occur in as many as up to $12 \%$ of individuals with other documented congential heart abnormalities [124-126]. The most common associated congential heart abnormalities are atrial septal defect and ventricular septal defect, followed by aortic coarctation, transposition of the great vessels, Tetralogy of Fallot, and anomalous connections of the pulmonary veins $[43,124,126]$. Conversely, the most frequently associated extra-cardiac anomaly is esophageal atresia [43].

\section{Anatomic variations of PLSVC}

PLSVC can occur in several anatomic variations. Most commonly, PLSVC coexists with a right SVC in up to $80 \%$ to $90 \%$ of cases [43]. While in many cases, these bilateral SVCs are of relatively equal size, various degrees of size differential can exist between that of the right SVC and the PLSVC [43]. In the instance of bilateral SVCs, a left innominate vein may be completely absent in up to approximately $65 \%$ of such cases [42]. In approximately $80 \%$ to $92 \%$ of cases of PLSVC, the PLSVC $[42,43,103]$ drains into the right atrium via the coronary sinus, resulting in no hemodynamic consequence. Conversely, in approximately $10 \%$ to $20 \%$ of cases of PLSVC, the PLSVC can drain via the left atrium, either through an unroofed coronary sinus or in a straight line fashion into the roof of the left atrium or through the left superior pulmonary vein $[43,44,111]$. In the instance of bilateral SVCs, the right SVC generally drains normally into the right atrium [43]. When a PLSVC is identified, the right SVC can be absent in approximately $10 \%$ to $20 \%$ of cases $[23,41,43,44,60,99,121]$.

\section{Venous imaging modalities}

If it is suspected that a patient has a PLSVC at the time of attempted central venous access device placement, 
then it is essential for that patient to undergo subsequent appropriate investigations to fully characterize their central venous anatomy. This is important in order to confirm the presence of PLSVC, to characterize the central venous anatomy of the contralateral right side, to characterize the pattern of cardiac venous return to the right atrium or to the left atrium, and to evaluate the patient for other potential coexisting congential heart abnormalities. Multiple venous imaging modalities can be utilized, as well as used in concert with one another, to accomplish complete characterization of the central venous anatomy. These venous imaging modalities include conventional contrast venography, transthoracic echocardiography, transesophageal echocardiography, multidetector computed tomography venography, and magnetic resonance venography $[2,3,41,89,127-134]$. Conventional contrast venography can be performed in the operating room (most commonly available by using single-image, non-digital subtraction intraoperative fluoroscopy techniques and less commonly available by digital subtraction intraoperative venography) or in the interventional radiology suite (generally always available by digital subtraction venography). Along similar lines, these venous imaging modalities can be utilized upfront prior to attempted central venous access device placement, if a patient is suspected of having pre-existing treatment-induced or diseaseinduced alterations in central venous anatomy.

\section{Clinical relevance of PLSVC to central venous access device placement}

As previously mentioned, the incidental finding of a PLSVC during central venous access device placement is of great potential importance to surgeons, interventional radiologists, and other physicians who are actively involved in central venous access device placement in cancer patients. With PLSVC occurring in only $0.3 \%$ to $0.5 \%$ of individuals in the general population and since there is theoretically only a $50 \%$ chance of encountering a PLSVC in an individual who has a PLSVC (by assuming that $50 \%$ of PLSVCs would be missed by a physician selecting the right side instead of the left side as the site of insertion of any given central venous access device), then it is very plausible that most physicians who place central venous access devices in their clinical practice may possible never, or only once, come across this congenital venous anomaly during their careers. In this regard, a resultant patient outcome in this rarely encountered scenario could potentially be devastating if the possibility of PLSVC was not thought of and/or not recognized by the physician at the time of a "difficult" central venous access device placement procedure.

It is important to discuss the implications of PLSVC as it applies to the pattern of cardiac venous return (i.e., to the right atrium or to the left atrium) in any given patient suspected of PLSVC at central venous access device placement. As previously discussed, the venous return from the PLSVC drains into the left atrium in approximately $10 \%$ to $20 \%$ of cases $[43,44,111]$. This particular venous drainage pattern of PLSVC that results in venous return to the left atrium $[34,40,43,44,65,81,92,98,100,111,113]$, as well as any other cardiac anomaly which results in right-to-left cardiac shunting, places those patients at a significant risk for subsequent paradoxical embolic complications to the arterial system, either from thromboemboli or air emboli, with resultant neurologic, cardiac, renal, mesenteric, and/or peripheral sequelae $[34,40,44,65,81,92,98,100,111,113,135,136]$. Therefore, it is essential that one fully characterizes, by venous imaging, the pattern of cardiac venous return (i.e., to the right atrium or to the left atrium) in any patient suspected of PLSVC at central venous access device placement prior to initiation of use of their central venous access device.

\section{Clinical indications for and relevance of venography during selected cases of attempted central venous access device placement: the surgeon's perspective and the interventional radiologist's perspective}

From the surgeon's perspective, intraoperative venography during attempted central venous access device placement can be a very useful tool for immediate characterization of central venous anatomy, including for recognition of congenital venous anomalies such as PLSVC, as well as for recognition of treatment-induced or disease-induced alterations in thoracic central venous anatomy. The use of intraoperative venography techniques during attempted central venous access device placement has been previously discussed in detail, from the surgeon's perspective, by one of the present authors for the venous cutdown approach and for the percutaneous venipuncture approach in cancer patients $[2,3]$, as well as has been previously discussed by other authors for the percutaneous venipuncture approach in hemodialysis patients [137]. Its use during attempted central venous access device placement should be considered in selected cases, such as in those instances in which there is difficulty with passing/advancing the guidewire or the central venous access catheter and in those instances in which aberrant catheter position is suspected [2,3]. In most operating room suites, intraoperative venography is generally performed using single-image, non-digital subtraction intraoperative fluoroscopy techniques, unless such an operating room suite is equipped with specialized digital subtraction fluoroscopy equipment.

From the surgeon's perspective, an important point of discussion regarding the performance of intraoperative 
venography during attempted central venous access device placement relates to the method of venous access (i.e., percutaneous venipuncture approach versus venous cutdown approach) and to the stepwise timing of intraoperative venography during attempted central venous access device placement [2,3]. In this regard, it should be clearly noted that the vast majority of surgeons still utilize the percutaneous venipuncture approach to either the left subclavian vein or right subclavian vein, with far fewer using the percutaneous venipuncture approach to either the right internal jugular vein or left internal jugular vein. Only a minority of surgeons utilize a venous cutdown approach, generally to either of the cephalic veins or external jugular veins, for central venous access device placement. Although readily available and endorsed by the American College of Surgeons [138], the vast majority of surgeons performing a percutaneous venipuncture approach to the subclavian vein or internal jugular vein still do not routinely utilize venous ultrasound to guide the placement of the venipuncture needle into the initial point of entry into the selected venous structure at the time of attempted central venous access device placement.

Performance of intraoperative venography by the surgeon via a venous cutdown approach (i.e., cephalic vein approach or external jugular vein approach) at the time of attempted central venous access device placement represents a very safe, straightforward, and highly useful means for obtaining detailed intraoperative characterization of the central venous anatomy $[2,3]$. By injecting contrast into the central venous access catheter with its tip located at the point of entry into the most peripheral venous conduit (i.e., cephalic vein or external jugular vein), and then sequentially advancing the catheter centrally, one can obtain a relatively detailed venous roadmap of the ipsilateral subclavian vein, innominate vein, and SVC, even when only single-image, non-digital subtraction intraoperative fluoroscopy techniques are available and employed.

On the other hand, performance of intraoperative venography by the surgeon via a percutaneous venipuncture approach (i.e., percutaneous subclavian vein approach or percutaneous internal jugular vein approach) at the time of attempted central venous access device placement has some intrinsic limitations [2,3]. Although the percutaneous venipuncture approach to central venous assess can also allow for the injection of contrast at the initial point of entry into the most peripheral venous conduit (i.e., subclavian vein or internal jugular vein), it is only possible during the early phases of the modified Seldinger technique when the venipuncture needle or an equivalent-sized dilator is still in place or even as far into the procedure as when the dilator and peel-away sheath apparatus are still in place (with or without the insertion of the central venous assess catheter). However, once the central venous access catheter has been passed through the peel-away sheath and advanced to its anticipated final central venous location at the junction of the SVC and right atrium, and the peel-away sheath has been subsequently peeled back off from the catheter, then intraoperative venography, in a practical sense, can only be performed through the tip of the already centrally placed catheter. At any time prior to peeling back the peel-away sheath, the central venous assess catheter and surrounding intact peel-away sheath can, to some degree, be manipulated and drawn back more peripherally for attempting intraoperative venography through the catheter tip positioned within a more peripheral portion of the central veins. Obviously, however, once the final positioning of the tip of the central venous access catheter is determined within the presumed most ideal location within the SVC region and is set by the process of peeling back the peel-away sheath during the modified Seldinger technique, then, if one attempts intraoperative venography, one simply tends to see only rapid contrast dissipation (i.e., washout) and the inability to obtain readable intraoperative fluoroscopic images when using singleimage, non-digital subtraction intraoperative fluoroscopy techniques. As previously discussed elsewhere [2], this very straightforward concept regarding the importance of catheter tip position within the central venous system and the practicality of performing intraoperative venography that will yield readable intraoperative fluoroscopic images has formerly failed to be recognized by surgeons and other physicians alike whom are involved in central venous access device placement in cancer patients [139]. However, in this particular instance, the availability of digital subtraction intraoperative fluoroscopy equipment in the operating room may provide the surgeon with an increased opportunity and likelihood for obtaining better intraoperative fluoroscopic images for attempting to possible define any central venous aberrancies. Nevertheless, such specialized digital subtraction intraoperative fluoroscopy equipment is rarely available to surgeons in most operating room suites, and for the most-part, the majority of operating room suites are still equipped with single-image, non-digital subtraction intraoperative fluoroscopy technology.

From the interventional radiologist's perspective, the approach to central venous access device placement and to venography is somewhat different than the surgeon's approach, as it relates to the method of venous access, the vein selection site, and the method of venography. In this regard, whereas surgeons primarily utilize the left subclavian vein or right subclavian vein percutaneous venipuncture approach (more commonly without ultrasound guidance), interventional radiologists almost 
exclusively utilize an ultrasound-guided right internal jugular vein percutaneous venipuncture approach, and alternatively an ultrasound-guided left internal jugular vein percutaneous venipuncture approach when there is a contraindication to central venous access device placement on the right side. After initial successful placement of the venipuncture needle by the ultrasound-guided right internal jugular vein or left internal jugular vein percutaneous venipuncture approach, the interventional radiologist passes the guidewire and watch the guidewire pass down through the thorax region under fluoroscopy and use the course of the guidewire and its behavior within the central veins as reasonable validation of standard/normal central venous anatomy. If there is any suspicious behavior by the guidewire (i.e., failure to advance the guidewire centrally into the SVC, or having the guidewire take a non-standard route), then the venipuncture needle is generally removed over the guidewire, a 5-French dilator is passed over the guidewire, the guidewire is then removed, and a venogram is performed. Injection of contrast into the 5-French dilator at this very peripheral initial point of entry into the right internal jugular vein or left internal jugular vein by the interventional radiologist will again allow for a relatively detailed venous roadmap of the ipsilateral internal jugular vein, subclavian vein, innominate vein, and SVC using digital subtraction intraoperative fluoroscopy equipment that is routinely available in the interventional radiology suite. Such an approach by the interventional radiologists has been developed out of necessity and in response to the increasing number of patients that are encountered with treatment-induced or diseaseinduced alterations in thoracic central venous anatomy.

\section{Clinical indications for and relevance of venous ultrasound during attempted central venous access device placement by way of the percutaneous venipuncture approach: the surgeon's perspective and the interventional radiologist's perspective}

It is well-established within the radiology [140], anesthesia [141], and surgical $[138,142]$ literature that venous ultrasound is a very useful and recommended imaging tool for guiding successful placement of the venipuncture needle into the initial point of entry of the selected venous structure, such as the subclavian vein or internal jugular vein, during the percutaneous venipuncture approach to central venous access device placement. While interventional radiologists have fairly universally embraced the use of venous ultrasound to help successfully guide the placement of the venipuncture needle into the initial point of entry of the selected venous structure during the percutaneous venipuncture approach to central venous access device placement in the interventional radiology suite, surgeons have been far more resistant to incorporating venous ultrasound into their repertoire for central venous access device placement in the operating room. Despite the proven usefulness of venous ultrasound for guiding successful placement of the venipuncture needle into the initial point of entry of the selected venous structure during the percutaneous venipuncture approach to central venous access device placement [138,140-142], it is nevertheless well recognized that venous ultrasound that is performed to the proximal upper extremity veins and central veins of the chest region can actually miss up to $50 \%$ of venous abnormalities that are otherwise clearly identifiable on conventional contrast venography $[2,3,137,143-147]$, including on intraoperative venography $[2,3,137]$. This is most easily explainable by the fact that many venous abnormalities of the upper extremity and central veins of the chest region are located in a more central location within the thoracic venous system (i.e., along the medial segment of the subclavian vein, along the innominate vein, or within the SVC), thus representing more centrally-located segments of the thoracic central venous anatomy which are not ideally accessible for visualization by standard venous ultrasound techniques $[2,3]$. Thus, from the surgeon's perspective, independent of whether or not one chooses to utilize venous ultrasound to guide the initial point of entry into the selected venous structure during the percutaneous venipuncture approach to central venous access device placement, the utilization of venography at the time of attempted central venous access device placement, by either a venous cutdown approach or a percutaneous venipuncture approach, can be an invaluable tool for defining the central venous anatomy and for providing a venous roadmap in particularly challenging cases in which difficulties are encountered during attempted central venous access device placement $[2,3,137]$.

\section{Conclusions}

A thorough understanding of venous anatomy, including the recognition of congenital venous anomalies (such as PLSVC) and the recognition of treatment-induced or disease-induced alterations in thoracic central venous anatomy, as well as having a good working knowledge of alternative and supplemental strategies for placement central venous access devices, are all critical factors to maximizing the success of central venous access device placement and to minimizing the risk of potential complications. A thorough understanding of these principles is of upmost importance to surgeons, interventional radiologists, and other physicians whom are actively involved in central venous access device placement in cancer patients. 
Specifically regarding PLSVC, it is critical to recognize its presence during attempted central venous access device placement and to fully characterize the pattern of cardiac venous return (i.e., to the right atrium or to the left atrium) in any patient suspected of PLSVC prior to initiation of use of their central venous access device.

\section{Consent}

Written informed consent was obtained from the patient for publication of this review paper and accompanying images. A signed copy of the written consent form from the patient is available for review by the Editor-in-Chief of this journal.

\section{Abbreviations}

PLSVC: persistent left superior vena cava; SVC: superior vena cava

\section{Author details}

'Division of Surgical Oncology, Department of Surgery, Arthur G. James Cancer Hospital and Richard J. Solove Research Institute and Comprehensive Cancer Center, The Ohio State University Medical Center, Columbus, Ohio, 43210, USA. '2 Section of Interventional Radiology, Department of Radiology, The Ohio State University Medical Center, Columbus, Ohio, 43210, USA.

\section{Authors' contributions}

SPP was the surgeon who performed the central venous access device placement procedure and the intraoperative venogram procedure. HK was the interventional radiologist who performed the postoperative venogram procedures. Both of the authors were involved in writing and editing this manuscript. Both of the authors have read and approved the final version of this manuscript.

\section{Competing interests}

The authors declare that they have no competing interests.

Received: 27 September 2011 Accepted: 28 December 2011 Published: 28 December 2011

\section{References}

1. Povoski SP: Long-term venous access. In Cancer Management: A Multidisciplinary Approach Medical Surgical and Radiation Oncology.. 11 edition. Edited by: Pazdur R, Wagman LD, Camphausen KA, Hoskins WJ. Lawrence, Kansas: CMPMedica (United Business Media); 2008:969-980.

2. Povoski SP: Eliminating the "Pitfalls" of chronic indwelling central venous access device placement in cancer patients by utilizing a venous cutdown approach and by selectively and appropriately utilizing intraoperative venography. Int Semin Surg Oncol 2007, 4:16.

3. Povoski SP, Zaman SA: Selective utilization of preoperative venous duplex ultrasound and intraoperative venography for central venous access device placement in cancer patients. Ann Surg Oncol 2002, 9:493-499.

4. Povoski SP: A prospective analysis of the cephalic vein cutdown approach for chronic indwelling central venous access in 100 consecutive cancer patients. Ann Surg Oncol 2000, 7:496-502.

5. Povoski SP: The external jugular vein cutdown approach for central venous access in cancer patients: A potentially useful alternative. World J Surg Oncol 2004, 2:7.

6. Marshall J: On the development of the great anterior veins in man and mammalia; including an account of certain remnants of foetal structure found in the adult, a comparative view of these great veins in the different mammalia, and an analysis of their occasional peculiarities in the human subject. Phil Trans Royal Soc 1850, 140:133-170.

7. Poynter CWM: Congenital anomalies of the arteries and veins of the human body. University Studies: Published by The University of Nebraska. Lincoln, Nebraska; 1922:22(1-2):1-106.
8. Bartholin T: Case histories of unusual anatomical and clinical structures, including descriptions and illustrations of anomalies and normal structures. Historiarum anatomicarum rariorum: Centuria I et II. , 1, Amsterdam:1641..

9. Hill RV: The contributions of the Bartholin family to the study and practice of clinical anatomy. Clin Anat 2007, 20:113-115.

10. Cheselden W: XXXVIII. Some Anatomical Observations. Phil Trans Royal Soc (1683-1775) 1713, 28:281-282.

11. Sanders MA: William Cheselden: anatomist, surgeon, and medical illustrator. Spine (Phila Pa 1976) 1999, 24:2282-2289.

12. Le Cat CN: Anatomie: Observations Anatomiques. Histoire De L'Académie Royale Des Sciences (Année MDCCXXXVIII) Paris: De L'Imprimerie Royale; 1740, 39-48.

13. Grise P: [Claude-Nicolas Le Cat (1700-1768), a famous surgeon and urologist of the 18th century]. Prog Urol 2001, 11:149-153, [French].

14. Fye WB: Albrecht von Haller. Clin Cardiol 1995, 18:291-292.

15. Boehmer PA: Specimen inaugurale anatómico-modicum de confluxu trium cavarum in dextro cordis atrio. Pro Gradu Doctoris Halae Magdeburg: ex officina Hendeliana; 1763, 527.

16. Murray A: Beschreibung einer gani sonderbaren Stellung und Vertheilung der obern Blutader des vordern Herzohrs. Neue Schwedische Akad Abhandl 1781, 283.

17. Carlsöö S: [Adolph Murray's chairmanship lecture in 1794, «A dissertation on the progress of anatomy in recent times»]. Nord Medicinhist Arsb 1991, 57-68, [Swedish].

18. PubMed.gov. [http://www.ncbi.nlm.nih.gov/pubmed].

19. Otto AW, South JF: Of the veins. A compendium of human \& comparative pathological anatomy London: B. Fellows; 1831, 335-355.

20. Ancel P, Villemin F: Sur la persistance de la veine cave supérieure gauche chez l'homme. Journal de l'anatomie et de la physiologie normales et pathologiques de l'homme et des animaux 1908, 44:46-62.

21. Hutton WK: An anomalous coronary sinus. J Anat Physiol 1915, 49:407-413.

22. McCotter RE: Three cases of the persistence of the left superior vena cava. Anat Rec 1916, 10:371-383.

23. Smith WC: A case of left superior vena cava without a corresponding vessel on the right side. Anat Rec 1916, 11:191-198.

24. Odgers PN: A Case of Bilateral Superior Venae Cavae in the Adult. J Anat 1928, 62(Pt 2):221-223.

25. Beattie J: The importance of anomalies of the superior vena cava in man. Can Med Assoc J 1931, 25:281-284.

26. Chouke KS: A case of bilateral superior vena cava in an adult. Anat Rec 1939, 74:151-157.

27. Prows MS: Two cases of bilateral superior venae cavae, one draining a closed coronary sinus. Anat Rec 1943, 87:99-105.

28. Saunders JM: Bilateral superior vena cavae. Anat Rec 1946, 94:657-662.

29. Steinberg I, Dubilier W Jr, Lukas DS: Persistence of left superior vena cava. Dis Chest 1953, 24:479-488.

30. Campbell M, Deuchar DC: The left-sided superior vena cava. Br Heart $J$ 1954, 16:423-439.

31. Winters FS: Persistent left superior vena cava; survey of world literature and report of thirty additional cases. Angiology 1954, 5:90-132.

32. Miller G, Inmon TW, Pollock BE: Persistent left superior vena cava. Am Heart J 1955, 49:267-274.

33. Harris WG: A case of bilateral superior venae cavae with a closed coronary sinus. Thorax 1960, 15:172-173.

34. Sarodia BD, Stoller JK: Persistent left superior vena cava: case report and literature review. Respir Care 2000, 45:411-416.

35. Biffi M, Boriani G, Frabetti L, Bronzetti G, Branzi A: Left superior vena cava persistence in patients undergoing pacemaker or cardioverterdefibrillator implantation: a 10-year experience. Chest 2001, 120:139-144.

36. Demos TC, Posniak HV, Pierce KL, Olson MC, Muscato M: Venous anomalies of the thorax. AJR Am J Roentgenol 2004, 182:1139-1150.

37. Gonzalez-Juanatey C, Testa A, Vidan J, Izquierdo R, Garcia-Castelo A Daniel C, Armesto V: Persistent left superior vena cava draining into the coronary sinus: report of 10 cases and literature review. Clin Cardiol 2004 27:515-518.

38. Peltier J, Destrieux C, Desme J, Renard C, Remond A, Velut S: The persistent left superior vena cava: anatomical study, pathogenesis and clinical considerations. Surg Radiol Anat 2006, 28:206-210. 
39. Paval J, Nayak S: A persistent left superior vena cava. Singapore Med J 2007, 48:e90-e93.

40. Erdoğan M, Karakaş P, Uygur F, Meşe B, Yamak B, Bozkir MG: Persistent left superior vena cava: the anatomical and surgical importance. West Indian Med J 2007, 56:72-76.

41. Heye T, Wengenroth M, Schipp A, Johannes Dengler T, Grenacher L, Werner Kauffmann G: Persistent left superior vena cava with absent right superior vena cava: morphological CT features and clinical implications. Int J Cardiol 2007, 116:e103-e105.

42. Goyal SK, Punnam SR, Verma G, Ruberg FL: Persistent left superior vena cava: a case report and review of literature. Cardiovasc Ultrasound 2008, 6:50.

43. Couvreur T, Ghaye B: Left superior vena cava. In Integrated Cardiothoracic Imaging with MDCT from Medical Radiology . Diagnostic Imaging and Radiation Oncology series.. 1 edition. Edited by: Rémy-Jardin M, Rémy J. Berlin · Heidelberg: Springer-Verlag; 2009:289-305.

44. Uçar O, Paşaoğlu L, Ciçekçioğlu H, Vural M, Kocaoğlu I, Aydoğdu S: Persistent left superior vena cava with absent right superior vena cava: a case report and review of the literature. Cardiovasc J Afr 2010, 21:164-166.

45. Rubenfire M, Evangelista J, Wajszczuk WJ, Kantrowitz A: Implication of a persistent left superior vena cava in transvenous pacemaker therapy and cardiac hemodynamic monitoring. Chest 1974, 65:145-147.

46. Coblentz MG, Criscito MA, Cohn JD: Persistent left superior vena cava complicating hemodynamic monitoring catheterization. Crit Care Med 1978, 6:32-35.

47. Crocker MC: Anomalous pulmonary arterial catheterization. Anesthesiology 1979, 51:574.

48. Falltrick RT: Pulmonary arterial catheterization through a persistent left supeior vena cava. Anesthesiology 1979, 50:155-156.

49. Yarnal JR, Smiley WH, Schwartz DA: Unusual course of a Swan-Ganz catheter. Diagnosis: persistent left superior vena cava (SVC). Chest 1979, 76:585-587.

50. Jantsch $H$, Draxler $V$, Muhar U, Schlemmer M, Waneck R: [Pseudodisplacement of the caval catheter in persistent left superior vena cava]. Rofo 1983, 138:41-44, [German].

51. Kiely EM, Spitz L: Persistent left superior vena cava and central venous feeding. Z Kinderchir 1984, 39:133-134.

52. Page $Y$, Tardy B, Comtet C, Bertrand M, Bertrand JC: [Venous catheterization and congenital abnormalities of the superior vena cava]. Ann Fr Anesth Reanim 1990, 9:450-455.

53. Lönnqvist PA, Olsson GL: Persistent left superior vena cava-an unusual location of central venous catheters in children. Intensive Care Med 1991 17:497-500.

54. Nand N, Scott SJ, Main J: Successful haemodialysis via an unusually sited subclavian catheter. Int J Artif Organs 1991, 14:97-98.

55. Paoletti F, Tesoro S, Boanelli A, Mosca S, Pozzilli P: [lsolated persistent left superior vena cava. Detection of cause during central venous catheterization]. Minerva Anestesiol 1991, 57:97-100, [Italian].

56. Schelling G, Briegel J, Eichinger K, Raum W, Forst H: Pulmonary artery catheter placement and temporary cardiac pacing in a patient with a persistent left superior vena cava. Intensive Care Med 1991, 17:507-508.

57. Leibowitz AB, Halpern NA, Lee MH, Iberti TJ: Left-sided superior vena cava: a not-so-unusual vascular anomaly discovered during central venous and pulmonary artery catheterization. Crit Care Med 1992, 20:1119-1122.

58. Oczenski W, Jellinek H, Winkelbauer F, Hackl W: [Pseudo-faulty location of a Swan-Ganz catheter in a persistent left superior vena cava]. Anaesthesist 1993, 42:473-476, [German].

59. Sweitzer BJ, Hoffman WJ, Allyn JW, Daggett WJ Jr: Diagnosis of a left-sided superior vena cava during placement of a pulmonary artery catheter. $J$ Clin Anesth 1993, 5:500-504.

60. Hara Y, Ota K, Fujita M, Suzuki H: Absence of right superior vena cava that was not detected by insertion of a pulmonary arterial catheter via the right internal jugular vein. J Clin Monit 1994, 10:210-212.

61. Josloff RK, Kukora JS: Central venous catheterization via persistent left superior vena cava. Am Surg 1995, 61:781-783.

62. Menéndez B, García del Valle S, Marcos RC, Azofra J, Gomez-Arnau J: Left superior vena cava: a vascular abnormality discovered following pulmonary artery catheterization. Can J Anaesth 1996, 43:626-628.

63. Chandra A, Reul GJ Jr: Persistent left superior vena cava discovered during placement of central venous catheter. Tex Heart Inst J 1998, 25:90.
64. Lai YC, Goh JC, Lim SH, Seah TG: Difficult pulmonary artery catheterization in a patient with persistent left superior vena cava. Anaesth Intensive Care 1998, 26:671-673.

65. Higgs AG, Paris S, Potter F: Discovery of left-sided superior vena cava during central venous catheterization. Br J Anaesth 1998, 81:260-261.

66. Kim YO, Choi EJ, Jeon HK, Han CH, Song HC, Yoon SA, Bang BK: Persistent left superior vena cava detected by hemodialysis catheterization. Nephron 1999, 83:87-88.

67. Stoiser B, Vorbeck F, Kofler J, Locker GJ, Burgmann H: Placement of a pulmonary artery catheter via a previously unrecognized persistent left superior vena cava. Vasa 1999, 28:53-54.

68. Greenberg M, Raggio C: Antecubital central venous catheter placement complicated by a persistent left superior vena cava. J Neurosurg Anesthesiol 2000, 12:114-117.

69. Ould-Ahmed M, Mas B, Hautbois E, Garcia JF, Caroff P, Guiavarch M: [Unusual course of a pulmonary artery catheter through a persistent superior vena cava]. Ann Fr Anesth Reanim 2000, 19:745-748, [French]

70. Marret E, Meunier JF, Dubousset AM, Pariente D, Samii K: [Diagnosis of a persistent left superior vena cava in the operating room during a central venous catheterization]. Ann Fr Anesth Reanim 2000, 19:191-194, [French].

71. Ferrer Gómez C, Silla Aleixandre I, Vicente Guillén R, Barrio Mataix J, Rodríguez Argente G, Montero Benzo R: [Persistent left superior vena cava: an infrequent localization of the central venous catheter]. Rev Esp Anestesiol Reanim 2001, 48:97-99, [Spanish].

72. Masuda Y, Imaizumi H, Satoh M, Hazama K, Nakamura M, Chaki R, Asai Y: [Persistent left-sided superior vena cava diagnosed after flow-directed pulmonary artery catheterization; report of a case]. Masui 2001, 50:1109-1112, [Japanese].

73. Azocar RJ, Narang P, Talmor D, Lisbon A, Kaynar AM: Persistent left superior vena cava identified after cannulation of the right subclavian vein. Anesth Analg 2002, 95:305-307.

74. de la Prada FJ, Sastre M, Forteza JF, Morey A, Munar MA, Alarcón A: [Persistence of the left superior vena cava discovered during the implantation of a hemodialysis catheter]. Nefrologia 2002, 22:199-201, [Spanish].

75. Huang YL, Wu MT, Pan HB, Yang CF: Aberrant course of Swan-Ganz catheter revealing persistent left superior vena cava. Zhonghua Yi Xue Za Zhi (Taipei) 2002, 65:403-406.

76. Radovic M, Masulovic D, Djukanovic L: Displacement of hemodialysis catheter in persistent left superior caval vein. Ren Fail 2002, 24:383-385.

77. Schummer W, Schummer C, Hoffmann E, Gerold M: Persistent left superior vena cava: clinical implications for central venous cannulation. Nutr Clin pract 2002, 17:304-308.

78. Schummer W, Schummer C, Reinhold L: [Differential diagnosis of leftsided thoracic venous catheters: case report of a persistent left superior vena cava]. Anaesthesist 2002, 51:726-730, [German].

79. Carrillo-Esper R, Contreras-Domínguez V, Salmerón-Nájera P, CarvajalRamos R, Hernández-Aguilar C, Juárez-Uribe A: [Persistent left superior vena cava: infrequent localization of central venous catheter]. Cir Cir 2003, 71:319-323, [Spanish].

80. Hachicha M, Cao-Huu T, Cordebar N, Canard L, Kessler M: Permanent catheter implantation via a persistent left superior vena cava. Nephrol Dial Transplant 2003, 18:1410-1411.

81. Kao CL, Chang JP: Malposition of a catheter in the persistent left superior vena cava. A rare complication of totally implantable venous devices. J Cardiovasc Surg (Torino) 2003, 44:145-147.

82. Laurenzi L, Natoli S, Pelagalli L, Marcelli ME, Abbattista D, Carpanese L, Arcuri E: Long-term central venous catheterization via persistent left superior vena cava: a case report. Support Care Cancer 2003, 11:190-192.

83. Pahwa R, Kumar A: Persistent left superior vena cava: an intensivist's experience and review of the literature. South Med J 2003, 96:528-529.

84. Schiffmann L, Kruschewski M, Wacker F, Buhr HJ: Persistent left superior vena cava: a reason for pseudodisplacement of a port catheter. Surg Radiol Anat 2003, 25:70-22.

85. Schummer W, Schummer C, Fröber R: Persistent left superior vena cava and central venous catheter position: clinical impact illustrated by four cases. Surg Radiol Anat 2003, 25:315-321.

86. Kamola PA, Seidner DL: Peripherally inserted central catheter malposition in a persistent left superior vena cava. J Infus Nurs 2004, 27:181-184. 
87. Kuppusamy TS, Balogun RA: Unusual placement of a dialysis catheter: persistent left superior vena cava. Am J Kidney Dis 2004, 43:365-367.

88. Schummer W, Schummer C, Steenbeck J: Central venous catheter in the left hemithorax-malpositioned? J Cardiothorac Vasc Anesth 2004, 18:529-531.

89. Danielpour PJ, Aalberg JK, El-Ramey M, Sivina M, Wodnicki H: Persistent left superior vena cava: an incidental finding during central venous catheterization-a case report. Vasc Endovascular Surg 2005, 39:109-111.

90. Hammerer V, Jeung M, Mennecier B, Demian M, Pauli G, Quoix E: [Duplication of the superior vena cava and other malformations discovered at insertion of a port-a-cath]. Rev Pneumol Clin 2005, 61:275-278, [French].

91. Konvicka JJ, Villamaria FJ: Images in anesthesia: anesthetic implications of persistent left superior vena cava. Can J Anaesth 2005, 52:805

92. Ghadiali N, Teo LM, Sheah K: Bedside confirmation of a persistent left superior vena cava based on aberrantly positioned central venous catheter on chest radiograph. Br J Anaesth 2006, 96:53-56.

93. Thompson C: Congenital cardiac malformations in relation to central venous access. Br J Nurs 2006, 15:276-281.

94. Treschan TA, Plicht B, Buck T, Beiderlinden M, Peters J: [Difficult placement of a pulmonary artery catheter due to a persistent left vena cava superior]. Anaesthesist 2006, 55:950-952, 954. [German].

95. Wasse H: Persistent left superior vena cava: diagnosis and implications for the interventional nephrologist. Semin Dial 2006, 19:540-542.

96. Fry AC, Warwicker P: Images in clinical medicine. Bilateral superior vena cava. N Engl J Med 2007, 356:1870.

97. Ranatunga DG, Richardson MG, Brooks DM: Percutaneous fluoroscopic removal of a knotted Swan-Ganz catheter in a patient with a persistent left-sided superior vena cava. Australas Radiol 2007, 51:182-185.

98. Shyamkumar NK, Brown R: Double superior vena cava with a persistent left superior vena cava: an incidental finding during peripherally inserted central catheter placement. Australas Radiol 2007, 51(Suppl): B257-B259.

99. Srivastava V, Mishra P, Kumar S, Jana S, Khandekar J, Agrawal N, Patwardhan AM: Persistent left SVC with absent right SVC: a rare anomaly. J Card Surg 2007, 22:535-536.

100. Stylianou K, Korsavas K, Voloudaki A, Patrianakos A, Vardaki E, Tzenakis N, Daphnis E: Can a left internal jugular catheter be used in the hemodialysis of a patient with persistent left superior vena cava? Hemodial Int 2007, 11:42-45.

101. Avolio L, Rinaldi A, Serafini G, Martucciello G: Endocavitary electrocardiography during central vein catheter positioning in a newborn with persistent left superior vena cava. J Vasc Access 2009 10:212-213.

102. Caruselli M, Piattellini G, Camilletti G, Giretti R, Pagni R: Persistent left superior vena cava in pediatric patients. J Vasc Access 2009, 10:219-220.

103. Granata A, Andrulli S, Fiorini F, Logias F, Figuera M, Mignani R, Basile A, Fiore CE: Persistent left superior vena cava: what the interventional nephrologist needs to know. J Vasc Access 2009, 10:207-211.

104. Jang YS, Kim SH, Lee DH, Kim DH, Seo AY: Hemodialysis catheter placement via a persistent left superior vena cava. Clin Nephrol 2009, 71:448-450.

105. Lacuey Lecumberri G, Ureña M, Martínez Basterra J, Basterra N: [Persistent left superior vena cava. Implications in central venous catheterisation]. An Sist Sanit Navar 2009, 32:103-106, [Spanish].

106. Luckianow G, Cole D, Kaplan L: Anatomical variant found during catheter insertion. JAAPA 2009, 22:60,63.

107. Orija A, Rajan J, Degenhard A: An interesting case: bilateral superior vena cava in a patient with end stage renal disease. Semin Dial 2009, 22:209-211.

108. Parreira LF, Lucas CC, Gil CC, Barata JD: Catheterization of a persistent left superior vena cava. J Vasc Access 2009, 10:214-215.

109. Baldirà Martínez de Irujo J, Núñez Vázquez El, Morán Chorro KA: [Central venous catheter insertion in a persistent left superior vena cava]. Med Intensiva 2010, 34:637, [Spanish].

110. Bordes J, Asencio Y, d'Arranda E, Goutorbe P: Persistent left vena cava incidentally recognized during subclavian vein catheterization. Crit Care 2010, 14:405.

111. Dinasarapu CR, Adiga GU, Malik S: Recurrent cerebral embolism associated with indwelling catheter in the presence of anomalous neck venous structures. Am J Med Sci 2010, 340:421-423.
112. Hsu KF, Yeh $\mathrm{CL}$, Huang GH, Chang HC, Tang SH: Aberrant central venous catheter-bilateral superior vena cava. J Trauma 2010, 69:E108.

113. Lim TC, H'ng MW: Persistent left superior vena cava: a possible site for haemodialysis catheter placement. Singapore Med J 2010, 51:e195-e197.

114. Perera NM, Sarko JA: A central line placed in an uncommon thoracic venous anomaly. J Emerg Med 2010, 38:374-375.

115. Sriramnaveen P, Krishna Kishore C, Sainaresh W, Sivaramakrishna G, Vijayalakshmi Devi B, Lakshmi AY, Sivakuma V: Placement of dual lumen non-cuffed dialysis catheter into persistent left superior vena cava. Clin Nephrol 2010, 73:81-82

116. Bouhbouh S, Omloo JM: [A man with abnormal blood vessels.]. Ned Tijdschr Geneeskd 2011, 155:A1726, [Dutch].

117. Commandeur D, Garetier M, Giacardi C, Huynh S, Deserts MD, BuguetBrown ML, Ould-Ahmed M, Rousset J: Ultrasound-guided cannulation of the left subclavian vein in a case of persistent left superior vena cava. Can J Anaesth 2011, 58:471-472.

118. Kute VB, Vanikar AV, Gumber MR, Shah PR, Goplani KR, Trivedi HL: Hemodialysis through persistent left superior vena cava. Indian J Crit Care Med 2011, 15:40-42.

119. Romero-Puche AJ, Castro-Arias R, Vera G, Wilchez A, Castilla A: CatheterRelated Thrombosis in Left Superior Vena Cava. Rev Esp Cardiol 2011.

120. Awad H, Ladson SV, Wingate JR, Eldayem MA, Hudec KJ, de Christenson MR, Hummel JD: Inadvertent placement of a pulmonary artery catheter in the coronary sinus: is it time to increase our sweep speed? J Clin Anesth 2011, 23:492-497.

121. Korkmaz L, Akyüz AR, Erkuş ME, Topal C: Isolated persistent left superior vena cava with absent right superior vena cava in two cases. Turk Kardiyol Dern Ars 2011, 39:501-504.

122. Fares WH, Birchard KR, Yankaskas JR: Persistent Left Superior Vena Cava Identified During Central Line Placement: A Case Report. Respir Med CME 2011, 4:141-143.

123. Verniquet A, Kakel R: Persistent left superior vena cava: implications during central venous cannulation. Can J Anaesth 2011.

124. Buirski G, Jordan SC, Joffe HS, Wilde P: Superior vena caval abnormalities: their occurrence rate, associated cardiac abnormalities and angiographic classification in a paediatric population with congenital heart disease. Clin Radiol 1986, 37:131-138.

125. Sipila W, Kakkila J, Heikel PE, Kyllonen KE: Persistent left superior vena cava. Ann Med Intern Fenn 1955, 44:251-261

126. Kula S, Cevik A, Sanli C, Pektas A, Tunaoglu FS, Oguz AD, Olgunturk R: Persistent left superior vena cava: experience of a tertiary health care center. Pediatr Int 2011, doi: 10.1111/j.1442-200X.2011.03443.x.

127. Chasen $\mathrm{MH}$, Charnsangavej C: Venous chest anatomy: clinical implications. Eur J Radiol 1998, 27:2-14.

128. Lawler LP, Fishman EK: Thoracic venous anatomy multidetector row $C T$ evaluation. Radiol Clin North Am 2003, 41:545-560.

129. Pálinkás A, Nagy E, Forster T, Morvai Z, Nagy E, Varga A: A case of absent right and persistent left superior vena cava. Cardiovasc Ultrasound 2006, 4:6.

130. Ou P, Celermajer DS, Calcagni G, Brunelle F, Bonnet D, Sidi D: Threedimensional CT scanning: a new diagnostic modality in congenital heart disease. Heart 2007, 93:908-913.

131. Kim CY, Merkle EM: Time-resolved MR angiography of the central veins of the chest. AJR Am J Roentgenol 2008, 191:1581-1588.

132. Lim ZS, Vettukattil JJ: Role of echocardiography in the assessment of adolescents and adults with congenital heart disease. Minerva Cardioangiol 2009, 57:389-413.

133. Paul JF, Rohnean A, Sigal-Cinqualbre A: Multidetector CT for congenital heart patients: what a paediatric radiologist should know. Pediatr Radiol 2010, 40:869-875.

134. Kowalski M, Maynard R, Ananthasubramaniam K: Imaging of persistent left sided superior vena cava with echocardiography and multi-slice computed tomography: implications for daily practice. Cardiol J 2011, 18:332-336.

135. Zuha R, Price T, Powles R, Treleaven J: Paradoxical emboli after central venous catheter removal. Ann Oncol 2000, 11:885-886.

136. Kaladji A, Gérard F, Audinet C, Cardon A: [Paradoxical embolism and ischemia of the digestive tract]. J Mal Vasc 2008, 33:247-249, [French].

137. Taal MW, Chesterton L, Mclntyre CW: Venography at insertion of tunnelled internal jugular vein dialysis catheters reveals significant occult stenosis. Nephrol Dial Transplant 2004, 19:1542-1545. 
138. American College of Surgeons Website: ST-60: Revised statement on recommendations for use of real-time ultrasound guidance for placement of central venous catheters.[http://www.facs.org/fellows_info/ statements/st-60.html], (last revised by the American College of Surgeons Committee on Perioperative Care and approved by the Board of Regents in February 2011).

139. Wyles SM, Browne G, Gui GP: Pitfalls in Portacath location using the landmark technique: case report. Int Semin Surg Oncol 2007, 4:13.

140. Tan PL, Gibson M: Central venous catheters: the role of radiology. Clin Radiol 2006, 61:13-22.

141. Kumar A, Chuan A: Ultrasound guided vascular access: efficacy and safety. Best Pract Res Clin Anaesthesiol 2009, 23:299-311.

142. Khoo SW, Han DC: The use of ultrasound in vascular procedures. Surg Clin North Am 2011, 91:173-184

143. Perry $\sqcup$, Sheiman RG, Hartnell GG: Interventional radiology and cross sectional imaging in venous access. Surg Oncol Clin N Am 1995, 4:505-535.

144. Forauer AR, Glockner JF: Importance of US findings in access planning during jugular vein hemodialysis catheter placements. J Vasc Interv Radiol 2000, 11:233-238.

145. Male C, Chait P, Ginsberg JS, Hanna K, Andrew M, Halton J, Anderson R, McCusker P, Wu J, Abshire T, Cherrick I, Mahoney D, Mitchell L: Comparison of venography and ultrasound for the diagnosis of asymptomatic deep vein thrombosis in the upper body in children: results of the PARKAA study. Prophylactic Antithrombin Replacement in Kids with ALL treated with Asparaginase. Thromb Haemost 2002, 87:593-598.

146. Brown PW: Preoperative radiological assessment for vascular access. Eur $J$ Vasc Endovasc Surg 2006, 31:64-69.

147. Hyland K, Cohen RM, Kwak A, Shlansky-Goldberg RD, Soulen MC, Patel AA, Mondschein JI, Solomon JA, Stavropoulos SW, Itkin M, Yeh H, Markmann J, Trerotola SO: Preoperative mapping venography in patients who require hemodialysis access: imaging findings and contribution to management. J Vasc Interv Radiol 2008, 19:1027-1033.

doi:10.1186/1477-7819-9-173

Cite this article as: Povoski and Khabiri: Persistent left superior vena cava: Review of the literature, clinical implications, and relevance of alterations in thoracic central venous anatomy as pertaining to the general principles of central venous access device placement and venography in cancer patients. World Journal of Surgical Oncology 2011 9:173.

\section{Submit your next manuscript to BioMed Central and take full advantage of:}

- Convenient online submission

- Thorough peer review

- No space constraints or color figure charges

- Immediate publication on acceptance

- Inclusion in PubMed, CAS, Scopus and Google Scholar

- Research which is freely available for redistribution

Submit your manuscript at www.biomedcentral.com/submit 